\title{
Among-population divergence in personality is linked to altitude in plateau pikas (Ochotona curzoniae)
}

\author{
Jiapeng $\mathrm{Qu}^{1,4,5^{*}} \mathbb{D}$, Denis Réale ${ }^{2}$, Quinn E. Fletcher ${ }^{3}$ and Yanming Zhang ${ }^{1}$
}

\begin{abstract}
Background: Animals inhabiting high altitudes consistently show slow life-histories. The pace-of-life syndrome (POLS) hypothesis posits behavioural, physiological and/or morphological traits that mediate the trade-off between current and future reproduction or survival, which have coevolved along a slow-fast life history continuum. Previous studies have shown that the life histories of plateau pikas varied across altitude, high-altitude individuals showed slow pace of life which were characterized by few litters per year with small litter sizes. Thus, we hypothesized that pikas populations at higher altitudes would also express personalities characteristic associated with slow life history, such as high sociability, low activity or aggressiveness. We tested this hypothesis by comparing the activity and docility of three plateau pika (Ochotona curzoniae) populations distributed along an altitudinal gradient of the Tibetan Plateau. We predicted that high-altitude pika would be more docile and less active.

Results: The behaviour of 556 pikas, from which 120 individuals were measured at least twice, was quantified. We observed that plateau pikas at high altitudes were less active and more docile than pika at lower altitudes. Activity and docility were significantly and negatively correlated in populations from high altitudes but not in populations from low altitudes.
\end{abstract}

Conclusions: Our results support the POLS hypothesis, highlight the existence of personality variation among populations distributed along an altitudinal gradient and emphasise the importance of environmental selection on personality divergence.

Keywords: Altitude, Life history, Pace-of-life syndrome, Personality

\section{Background}

Species with wide ranges usually exhibit geographic variation in life history traits, such as growth and reproduction [1-3]. Geographic variation in life history traits is becoming an important avenue for research in ecology and evolutionary biology $[4,5]$. Geographic variation in life history traits arises from intrinsic factors (i.e. genetic and/or genomic divergence amongst populations) or extrinsic factors (e.g. temperature, precipitation, food availability and predation) [6-8]. Selection operates in

\footnotetext{
* Correspondence: jpqu@nwipb.cas.cn

${ }^{1}$ Key laboratory of adaptation and evolution of plateau biota, Northwest Institute of Plateau Biology, Chinese Academy of Sciences, Qinghai 810008, China

${ }^{4}$ State Key Laboratory of Grassland Agro-ecosystems SKLGAE, Lanzhou University, Lanzhou 730000, China

Full list of author information is available at the end of the article
}

different directions and/or with differing strengths across the geographic range of species, resulting in distinct life history strategies contributing to local adaptation.

Populations inhabiting altitudinal gradients experience distinct environmental conditions and show divergent traits in response to these conditions. With an increase in altitude, ambient temperature and growing season duration and biomass decrease, and plant phenology is delayed [9]. Specific species with wide altitudinal ranges adopt altitude-specific life-history strategies, commonly showing slower life histories with increasing altitude [9, 10]. For example, dark-eyed Juncos (Junco hyemalis) bred at high elevations showed delayed development of structures necessary for reproduction, reduced duration of reproductive period and fewer broods than lowelevation conspecifics [10, 11]. Moreover, amphibians and mammals at higher elevations exhibit shorter

(c) The Author(s). 2019 Open Access This article is distributed under the terms of the Creative Commons Attribution 4.0 International License (http://creativecommons.org/licenses/by/4.0/), which permits unrestricted use, distribution, and 
breeding seasons, longer larval periods and fewer litters per year with lower litter sizes compared with individuals at lower elevations $[2,12]$.

The pace-of-life syndrome (POLS) hypothesis posits that any trait (behavioural, physiological or morphological) that mediates trade-off between current and future fitness should coevolve with the life-history traits along the slow-fast life-history continuum [13-15]. The narrow-sense version of the POLS hypothesis [14] predicts that a fast pace of life, which is characterized by a short lifespan, an early age of first reproduction and a fast growth rate, is associated with a more bold, active and aggressive personality type that explores the environment in a cursory manner [16-18]. Individuals inhabiting populations exposed to differing environmental conditions are assumed to show different pace-of-life types [19-23]. For example, blue tits (Cyanistes caeruleus) living in habitats that are either resource rich or poor show divergence in their life histories, activity and docility following the predictions of the POLS hypothesis $[24,25]$. Ant (Temnothorax longispinosus) colonies from warmer areas are more exploratory and less aggressive than ants from colder areas [26]. Although numerous studies have described altitude-associated variation in life histories [11, 27], no study has examined personality variation along an altitudinal gradient. A limited number of studies have also analysed personality divergence among populations living in different habitats $[24,26]$.

Here, we test the hypothesis that the mean level of personality change with altitude by comparing activity and docility of three plateau pika (Ochotona curzoniae) populations distributed along an altitudinal gradient [28]. Although the altitude difference between highest and lowest sites is about $700 \mathrm{~m}$, annual and maximum monthly average temperature and vegetation conditions show distinct differences among sites (Table 1). Earlier research has shown that pika populations manifest slower life-histories at higher altitudes characterized by fewer litters per year with lower litter sizes and a shorter breeding season compared with populations at lower altitudes [29-34]. We predicted that high-altitude populations would be characterised by slower individuals, which are characterized by more thorough activity and lower docility, than high-altitude populations [13].

\section{Methods}

\section{Study system}

The plateau pika is a small, diurnal lagomorph that is widely distributed throughout the alpine meadows of the Tibetan Plateau. Populations can live between altitudes of 3,200 and 5,300 $\mathrm{m}$ [35]. Pikas live communally forming territorial, mixed-sex groups that use a distinct burrow system with multiple entries [33]. Previous studies have shown population divergence in life history traits at different altitudes [29-33, 36-41]. For example, lowaltitude populations (e.g. Guinan, 3,200 m) produce 3-5 litters per year with $4.5 \pm 0.1$ pups in each litter [31,37], whereas those from high-altitude (e.g. Guoluo, 4,000 m) produce $1-2$ litters per year with $3.2 \pm 0.1$ pups in each litter [32, 34].

We investigated three plateau pika populations at three different altitudes: Maqin (MQ), Zeku (ZK) and

Table 1 Geographic, climatic, vegetation and pika life history characteristics of three sites in the eastern Tibetan Plateau (China)

\begin{tabular}{|c|c|c|c|c|}
\hline \multirow[t]{2}{*}{ Traits } & & \multicolumn{3}{|c|}{ Populations/ sites } \\
\hline & & Maqin (MQ) & Zeku (ZK) & Guinan (GN) \\
\hline \multirow[t]{3}{*}{ Geography $^{a}$} & Latitude (N) & $34^{\circ} 24^{\prime}$ & $35^{\circ} 01^{\prime}$ & $35^{\circ} 28^{\prime}$ \\
\hline & Longitude (E) & $100^{\circ} 21^{\prime}$ & $101^{\circ} 27^{\prime}$ & $101^{\circ} 08^{\prime}$ \\
\hline & Altitude (m) & 3984 & 3694 & 3307 \\
\hline \multirow[t]{5}{*}{ Climate $^{\mathrm{b}}$} & Annual precipitation (mm) & 528 & 477.48 & 407.8 \\
\hline & Annual avg. temperature $\left({ }^{\circ} \mathrm{C}\right)$ & -0.19 & 0.41 & 2.3 \\
\hline & Min. monthly avg. temperature $\left({ }^{\circ} \mathrm{C}\right)$ & -12.6 & -12.3 & -11.5 \\
\hline & Max. monthly avg. temperature $\left({ }^{\circ} \mathrm{C}\right)$ & 9.7 & 6.74 & 13.2 \\
\hline & Annual sunshine duration (hs) & 2260 & 2620.47 & 2701 \\
\hline \multirow[t]{3}{*}{ Vegetation $^{a}$} & $\operatorname{Cover}^{\mathrm{c}}(\%)($ mean $\pm \mathrm{SE})$ & $75.2 \pm 2.87$ & $78.8 \pm 3.05$ & $85.8 \pm 3.66$ \\
\hline & Height $^{\mathrm{c}}(\mathrm{cm})($ mean $\pm \mathrm{SE})$ & $3.06 \pm 0.23$ & $3.2 \pm 0.12$ & $4.0 \pm 0.19$ \\
\hline & Growing season (days) & $90-110$ & $100-110$ & $120-130$ \\
\hline \multirow[t]{4}{*}{ Life history } & Breeding season & Apr.-Jun. ${ }^{[28]}$ & Apr.-Jun. ${ }^{a}$ & Apr.-Jul. ${ }^{[22,23,30]}$ \\
\hline & Litters per year & $1-2$ & $1-2$ & $2-3$ \\
\hline & Litter size (Mean $\pm \mathrm{SE})$ & $3.2 \pm 0.1^{[22]}$ & $4.4 \pm 0.3^{a}$ & $4.5 \pm 0.1^{[19]}$ \\
\hline & Annual survival rate (\%) & $33.5-50.3^{[22]}$ & - & $23.4-28.6^{[30]}$ \\
\hline
\end{tabular}

${ }^{a}$ data in present study, ${ }^{\mathrm{b}}$ climatic data obtained from the Qinghai Meteorological Bureau

${ }^{c}$ vegetation cover and heights in GN were significantly higher when those in ZK and MQ (all $p<0.05$ ) 
Guinan (GN), in the eastern Tibetan Plateau, Qinghai, China (Fig. 1). The distances between sites ranged from $180 \mathrm{~km}$ to $285 \mathrm{~km}$, and the normal dispersal distance of plateau pika is about $40 \mathrm{~m}$ [42]; therefore, gene flow among the three populations is limited. At all sites, the climate is dry and cool, typical of a plateau continental climate [43]. Precipitation occurs mostly from May to September, and heavy winter snowfalls are rare. Daily temperatures vary considerably (up to $25^{\circ} \mathrm{C}$ ). The climate is harsher at higher altitudes with decreasing annual temperatures, whereas annual precipitation increases. As a result, productivity and vegetation height decreases, and the growing season becomes shorter at higher altitudes (Table 1).

Vegetation at the three sites is typical of Tibetan alpine meadows. The dominant plant species include Kobresia humilis, Elymus nutans Griseb. and Leontopodium alpinum. To evaluate vegetation at each site, we quantified plant cover and height using the approach developed by Huenneke et al. [44]. At each site, 10 quadrats $(50 \mathrm{~cm} \times 50 \mathrm{~cm})$ were randomly selected. We estimated plant biomass within each quadrat using nondestructive measurements of plant species cover and height and total vegetation cover by counting the portions of squares occupied by plants. Vegetation height was presented as the mean height of each species. With the increase in altitude, vegetation cover and height were significantly higher at GN than at GL and ZK (Table 1).

At all sites, grass is grazed all year round by livestock (i.e. yak, sheep and horse). Other small herbivores, such as woolly hares (Lepus oiostolus), Himalayan marmots (Marmota himalayana) and plateau zokors (Myospalax baileyi), were absent at the sites. Common predators include red fox (Vulpes vulpes), Tibetan fox ( $V$. ferrilata), upland buzzard (Buteo hemilasius) and saker falcon (Falco cherrug).

\section{Animal marking}

The study area at each site measured 1.0 ha $(100 \mathrm{~m} \times$ $100 \mathrm{~m}$ ). The study period was divided into two stages: breeding (June) and nonbreeding season (August). We caught pikas using string nooses, which were anchored into the soil with chopsticks (i.e. a chopstick with a loop of string with a slipknot that tightens around the neck of the pika), set up at multiple entries to the burrow system. This method is widely used in live-trapping of both lizards and mammals and causes no significant negative effects on the behaviour of animals [28, 29, 45]. Over 2005 to 2018 of research at these sites, no pikas have been accidently injured nor killed by the string nooses $[28,33,34]$. Live traps were set at 07:00-09:00, constantly observed from $30 \mathrm{~m}$ away by a field technician, and retrieved at approximately 13:00. Trapped individuals were extracted from the nooses within approximately $30 \mathrm{~s}$ after capture. Pikas were weighed, and their sex and reproductive status (active or inactive) was examined by checking their reproductive organs. We then determined the approximate age of each individual based on their body mass, fur colour and toe hardness [33]. Individuals were divided into two age classes: adults (born during the previous year) and juveniles (born during the year of the study). Individuals were marked using hand-made aluminium ear tags stamped with a unique number code for permanent identification (ID).

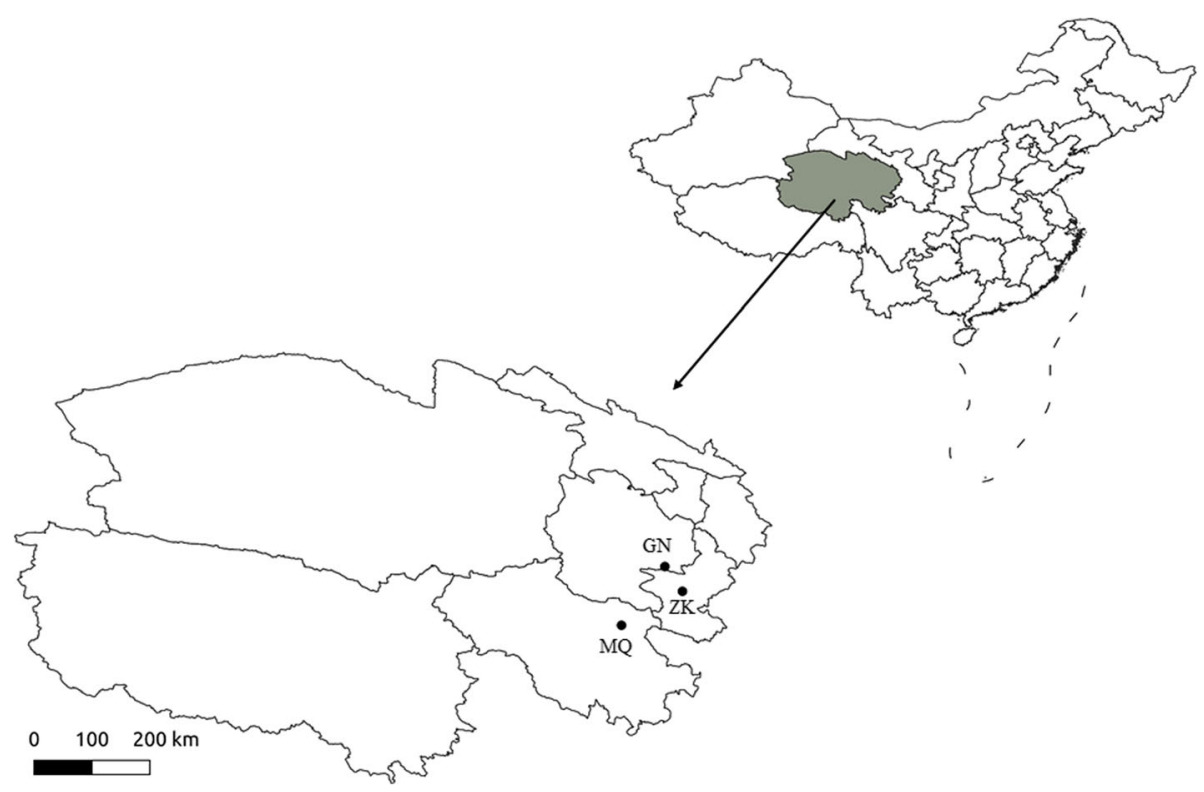

Fig. 1 Map showing the locations of the study sites indicated by abbreviations corresponding to Table 1 
All individuals were released on the study grid where they were captured.

\section{Behavioural tests}

We conducted behavioural assays on recapture events on different days following the first capture when individuals were marked. After capturing, a field technician immediately transported the pikas to a processing location located $\sim 30 \mathrm{~m}$ off the trapping grid. Animals were transported in mash bags, and $\sim 1$ min was needed to reach the processing location. At the processing location, the behaviour of the pika was immediately examined according to the following sequence:

(1) Bag test: The pika was transferred into a mesh bag $(20 \mathrm{~cm} \times 40 \mathrm{~cm})$. We used the number of seconds the pika remained immobile during $1 \mathrm{~min}$ as an index of docility [46].

(2) Open field test: Pikas were transferred from the mesh bag into an open field arena. The arena was a wood box $(100 \mathrm{~cm} \times 100 \mathrm{~cm} \times 100 \mathrm{~cm})$, painted white and with grid $(10 \mathrm{~cm} \times 10 \mathrm{~cm})$ lines drawn on the floor. We recorded open field trails for $120 \mathrm{~s}$ using a digital video camera fixed on a tripod. The pikas were then removed from the arena, and their ID were recorded. Pikas were then released at their location of capture. After each trial, the arena was cleaned using $75 \%$ alcohol and air-dried prior to the subsequent trial. Using EthoVision XT 9.0 (Noldus Information Technology), we measured the distance covered by each pika $(\mathrm{cm})$ as an index of activity [17, 47]. Individuals from MQ were tested in June $(n=165)$ and August $(n=205) 2013$, individuals from GN were tested in June $2013(n=17)$ and August 2014 $(n=31)$, whereas those from ZK were tested in June $(n=72)$ and August $(n=66) 2014$. The interval time between repeated tests range from 75 to 104 days in three populations.

\section{Statistical analyses}

Overall, the behaviour of 556 pikas, from which 120 individuals were measured twice, was quantified. Univariate linear mixed models (LMM) were used to test for phenotypic differences among populations and to estimate the repeatability of two traits. All univariate LMMs analyses were conducted using the $\mathrm{R}$ package MCMCglmm [48, 49]. For each model, we included population, sex, season (breeding versus nonbreeding) and age (juvenile versus adult) as fixed effects in addition to the random effects of ID and test date. We uses an inverse-Gamma distribution as the prior for variance components, the set of parameters were $\mathrm{nu}=$ 1.002 , and $V=2$ [49]. Models were run for $6,500,000$ iterations with a thinning interval of 5,000 and a burn-in of $1,500,000$. We determined the effects of traits based on whether their $95 \%$ credible intervals (CIs) overlapped with zero. We estimated repeatability and their 95\% CIs following the approach of Dingemanse et al. [48]. Studies have proven that within-individual correlations were negligible, and phenotypic correlations can represent among-individual correlations in plateau pika population [28], thus, we tested the phenotypic correlations in this study. Pearson's correlation tests were used when the original variables fitted a normal distribution or when log or square root transformation resulted in normality (Shapiro-Wilk test). Otherwise, Spearman's rank correlation test was used. All analyses were carried out using $R$ [50].

\section{Results}

Activity and docility were highly $(r=0.77, \mathrm{CI}=[0.70$, $0.81])$ and moderately $(r=0.46, \mathrm{CI}=[0.37,0.55])$ repeatable, respectively, indicating that variation in these two personality traits varies consistently among individuals over time.

Three populations at different altitudes showed our predicted differences in activity and docility (Table 2). Activity of high-altitude individuals (MQ) was lower than in intermediate-altitude (ZK) and low-altitude individuals (GN) (Fig. 2a). High-altitude individuals were the most docile, followed by individuals at intermediate and low altitudes (Fig. 2b). Activity was significantly negatively correlated with docility in the MQ $(r=-$ $0.172, P<0.001)$ and $\mathrm{ZK}(r=-0.432, P<0.001)$

Table 2 Univariate mixed models describing inter-population differences in personality traits across three plateau pika populations from the eastern Tibetan Plateau

\begin{tabular}{llll}
\hline Trait & Fixed effects & Estimate $(\mathrm{Cl} 95 \%)$ & Pmcmc \\
\hline Activity & Intercept & $23.97(22.03,26.11)$ & $<\mathbf{0 . 0 0 1}$ \\
& Population (ZK) & $7.85(4.76,10.81)$ & $<\mathbf{0 . 0 0 1}$ \\
& Population (GN) & $19.66(15.28,23.75)$ & $<\mathbf{0 . 0 0 1}$ \\
& Year & $4.44(-89.11,91.88)$ & 0.960 \\
& Sex (M) & $-11.44(--127.60,104.10)$ & 0.836 \\
& Season (NB) & $-1.06(-3.29,1.35)$ & 0.158 \\
& Age (J) & $-0.05(-2.23,2.37)$ & 0.792 \\
& Population & $2.12(-1.07,5.50)$ & 0.21 \\
(ZK) $\times$ Season (NB) & & $<\mathbf{0 . 0 0 1}$ \\
Intercept & $38.88(36.61,41.38)$ & $<\mathbf{0 . 0 0 1}$ \\
Docility & $-9.09(-13.54,-5.08)$ & $<\mathbf{0 . 0 0 1}$ \\
& Population (ZK) & $-18.36(-24.95,-11.54)$ & 0.080 \\
Population (GN) & $-8.67(-18.20,0.66)$ & 0.078 \\
Year & $-2.41(-4.85,0.23)$ & 0.096 \\
Sex (M) & $-2.96(-6.37,0.26)$ & 0.064 \\
Season (NB) & $-3.14(-6.08,0.28)$ & 0.178 \\
Age (J) & $-3.72(-9.12,1.76)$ & \\
Population & & \\
(ZK) $\times$ Season (NB) & & \\
\hline
\end{tabular}

Bold values indicate significant effect 


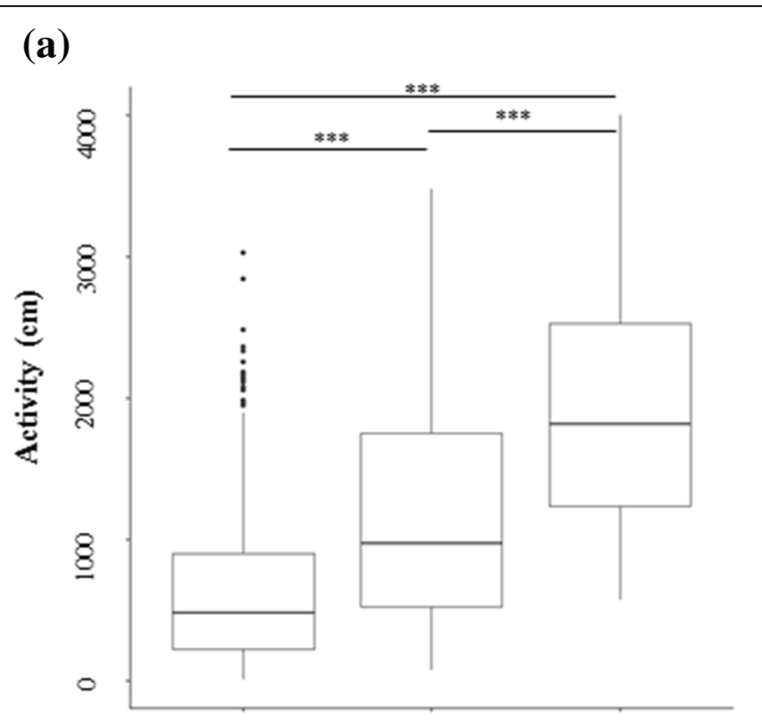

(b)

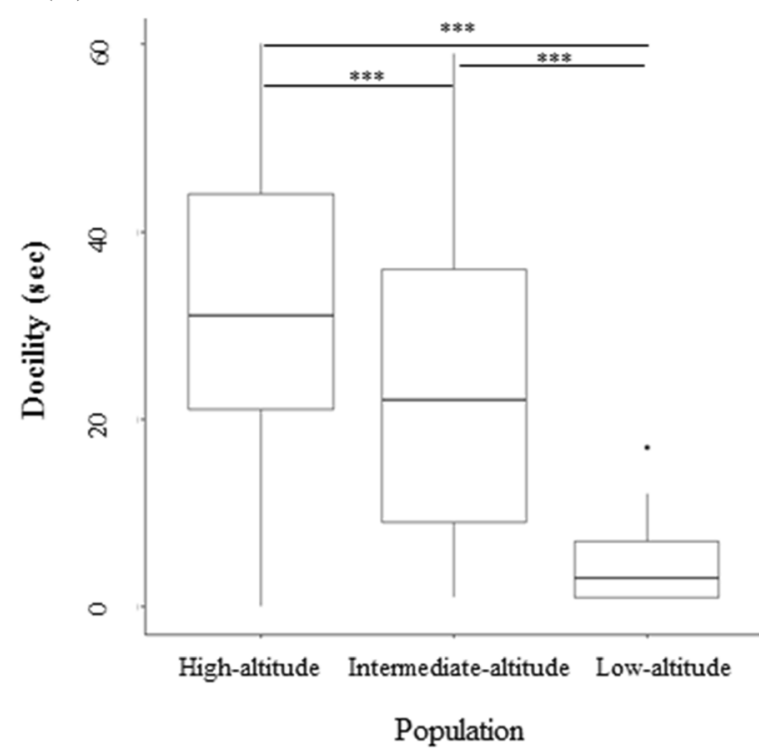

Fig. 2 Activity (a) and docility (b) of plateau pika individuals inhabiting populations at three altitudes in the Tibetan Plateau. ${ }^{* *_{*}{ }^{\prime \prime}}$ indicates a significant difference $(P<0.001)$ between two populations

populations but showed no correlation with docility in the $\mathrm{GN}(r=-0.286, P=0.118)$ population.

\section{Discussion}

We investigated the phenotypic divergence of personality traits among plateau pika populations along an altitudinal gradient. Previous work on plateau pika populations indicates that the life-histories of high-altitude populations are slow. In support of the POLS hypothesis, we observed that higher-altitude populations also possessed personality traits that have been characterized as slow, i.e., less active and more docile, compared with the lower-altitude populations.

The differences in activity and docility among plateau pika altitude-associated populations can be attributed to the differing life history strategies that have evolved in response to different climates and environments (Table 1). Low-altitude pikas from GN show high reproductive output, which may be correlated with behaviour associated with increased energy intake [13, 51]. Activity in the open field is associated with activity levels, which are required for foraging, mating and predator escape [52]. Docility is often used as a measure of risky behaviour in response to predator cues $[47,53]$. The thorough activity and low docility of pikas from GN (lowest altitude) may facilitate them to obtain sufficient energy to satisfy greater energy requirements for reproduction.

Our findings indicate that differences in environmental conditions resulted in specific associations between behavioural traits of plateau pikas. These results indicate that behavioural syndromes could be adaptive, such that associations between behaviour may vary substantially in accordance with prevailing environmental conditions. Activity and docility were negatively associated in pikas from high- and medium-altitude sites. Correlations between these traits may corroborate the POLS hypothesis [13]. In the Tibetan Plateau, an increase in altitude is associated with a decrease in temperature and food resources [54]. Environmental or animal status may affect relationships between behavioural and physiological traits [55]. Negative feedback mechanisms (e.g. asset protection hypotheses) may predominate at low resource levels and decouple such correlations. By contrast, positive feedback mechanisms between animal states and different behaviour (e.g. starvation avoidance or state-dependent safety hypotheses) at intermediate levels of resource availability can produce behavioural syndromes [56]. Our study implied that the directions of such relationships could be affected by altitude. In high-altitude populations, negative associations between activity and docility may be adaptive and enable pikas to obtain additional food resources and evade predation. Pikas from lowest sites occupy higher vegetation cover and food availability, which can weaken or eliminate the correlations between activity and docility in pika populations [26].

We analysed behavioural differences among populations at the phenotypic level. As a result, we cannot rule out whether phenotypic differences reflect genetic differences or developmental plasticity [25]. Regardless of the cause of differences among populations, our results suggest that the divergence in behaviour traits across the altitudinal gradient may enable pikas to cope with different local environments $[13,17]$. Reciprocal translocation or commongarden experiments would help to determine if personality 
differences reflect genetic differences or developmental plasticity [57-59].

We were unable to conclusively identify the precise divergences in the personality of pika populations distributed at higher altitudes, given that we focused on the traits of pika populations distributed within a limited altitude range. Nevertheless, our data reveal that the personality of pikas differs across altitudinal sites. Our study also provides valuable information regarding the effects of ecological conditions on the behavioural traits of animals at the population levels [13]. Although numerous studies have documented variation in life-history traits and phenotypes in response to global climate change [4], only a few have shown adaptations of animal personality to global warming $[26,60]$. Increases in altitude are associated with decreases in temperature, and changes in environments may reflect how animals will respond to future climate change [3]. Further studies illuminating the mechanisms underlying the personality differences among populations are necessary to improve our understanding of animal responses to future climate change [61-63].

\section{Conclusions}

Plateau pikas exhibit significant differences in activity and docility along the altitudinal gradient, supporting the POLS hypothesis. Future studies are needed to explore the mechanism and ecological consequences of personality divergences at large spatial-temporal scales and combine the animal personality with global climate changes.

\section{Abbreviations}

GN: Guinan; MQ: Maqin; POLS: pace-of-life syndrome; ZK: Zeku

\section{Acknowledgements}

We are grateful to Lai Yourong and Bai Zhaohong for their assistants in the wild. We appreciate the owners of the grasslands for allowing us to work at their properties.

\section{Authors' contributions}

$J Q$, DR and QF contributed to the design and implementation of this study JQ performed statistical analyses and wrote the manuscript; DR, QF and YZ provided feedback on the manuscript. All authors gave final approval for publication and agreed to be accountable for all aspects of the work.

\section{Funding}

This work was financially provided by the National Natural Science Foundation of China (31770459), State Key Laboratory of Grassland AgroEcosystems (Lanzhou University), Youth Innovation Promotion Association CAS, Applied and Basic Research Program of Qinghai Province (2017-ZJ-761), Thousand People Plan of Qinghai Province, Construction Fund for Qinghai Key Laboratories (2017-ZJ-Y23), Qinghai Provincial Key R \& D and Transformation Program (2019-SF-150). None of the authors have any competing interests in the manuscript.

\section{Availability of data and materials}

The dataset supporting the conclusions of this article are included in https:// doi.org/10.6084/m9.figshare.7357313.v1.

\section{Ethics approval and consent to participate}

Ethical approval was granted from Ethics Committee, Northwest Institute of Plateau Biology, CAS (NWIPB-2013-24).

\section{Competing interests}

The authors declare that they have no competing interests.

\section{Author details}

${ }^{1}$ Key laboratory of adaptation and evolution of plateau biota, Northwest Institute of Plateau Biology, Chinese Academy of Sciences, Qinghai 810008, China. ${ }^{2}$ Département des Sciences Biologiques, Université du Québec à Montréal, Montréal, QC H3P 3P8, Canada. ${ }^{3}$ Department of Biology and Centre for Forest Interdisciplinary Research (C-FIR), University of Winnipeg, Winnipeg, MB R3B 2E9, Canada. ${ }^{4}$ State Key Laboratory of Grassland Agro-ecosystems SKLGAE, Lanzhou University, Lanzhou 730000, China. ${ }^{5}$ Qinghai Provincial Key Laboratory of Animal Ecological Genomics, Qinghai 810008, China

Received: 12 February 2019 Accepted: 1 July 2019

Published online: 08 July 2019

\section{References}

1. Schmidt PS, Matzkin L, Ippolito M, Eanes WF. Geographic variation in diapause incidence, life-history traits, and climatic adaptation in drosophila melanogaster. Evolution. 2005;59:1721-32.

2. Morrison C, Hero J-M. Geographic variation in life-history characteristics of amphibians: a review. J Anim Ecol. 2003;72:270-9.

3. Liao WB, Luo Y, Lou SL, Lu D, Jehle R. Geographic variation in life-history traits: growth season affects age structure, egg size and clutch size in Andrew's toad (Bufo andrewsi). Front Zool. 2016;13:1-9.

4. Fritz SA, Bininda-Emonds ORP, Purvis A. Geographical variation in predictors of mammalian extinction risk: big is bad, but only in the tropics. Ecol Lett. 2009;12:538-49.

5. Both C, Artemyev AV, Blaauw B, Cowie RJ, Dekhuijzen AJ, Eeva T, et al. Large-scale geographical variation confirms that climate change causes birds to lay earlier. P Roy Soc Lond B Bio. 2004;271:1657-62.

6. English S, Bateman A, Clutton-Brock T. Lifetime growth in wild meerkats: incorporating life history and environmental factors into a standard growth model. Oecologia. 2012;169:143-53.

7. Andreo V, Lima M, Provensal C, Priotto J, Polop J. Population dynamics of two rodent species in agro-ecosystems of Central Argentina: intra-specific competition, land-use, and climate effects. Popul Ecol. 2009;51:297-306.

8. Barson NJ, Aykanat T, Hindar K, Baranski M, Bolstad GH, Fiske P, et al. Sexdependent dominance at a single locus maintains variation in age at maturity in salmon. Nature. 2015;528:405-8.

9. Hille $\mathrm{SM}$, Cooper CB. Elevational trends in life histories: revising the pace-oflife framework. Biol Rev. 2015;90:204-13.

10. Bears H, Martin K, White GC. Breeding in high-elevation habitat results in shift to slower life-history strategy within a single species. J Anim Ecol. 2009; 78:365-75.

11. Irene TB. High and low, fast or slow: the complementary contributions of altitude and latitude to understand life-history variation. J Anim Ecol. 2009; 78:293-5.

12. Laiolo P, Obeso JR. Life-history responses to the altitudinal gradient. In: Catalan J, Ninot JM, Aniz MM, editors. High mountain conservation in a changing world. Cham: Springer; 2017. p. 253-83.

13. Réale D, Garant D, Humphries MM, Bergeron P, Careau V, Montiglio P-O. Personality and the emergence of the pace-of-life syndrome concept at the population level. Philos Trans R Soc B Biol Sci. 2010;365:4051-63.

14. Montiglio P-O, Dammhahn M, Dubuc Messier G, Réale D. The pace-of-life syndrome revisited: the role of ecological conditions and natural history on the slow-fast continuum. Behav Ecol Sociobiol. 2018;72:116.

15. Wright J, Bolstad GH, Araya-Ajoy YG, Dingemanse NJ. Life-history evolution under fluctuating density-dependent selection and the adaptive alignment of pace-of-life syndromes. Biol Rev. 2019;94:230-47.

16. Rödel H, Zapka M, Talke S, Kornatz T, Bruchner B, Hedler C. Survival costs of fast exploration during juvenile life in a small mammal. Behav Ecol Sociobiol. 2015;69:205-17.

17. Montiglio P-O, Garant D, Pelletier F, Réale D. Intra-individual variability in fecal cortisol metabolites varies with lifetime exploration and reproductive life history in eastern chipmunks (Tamias striatus). Behav Ecol Sociobiol. 2015;69:1-11.

18. Wolf M, Van Doorn GS, Leimar O, Weissing FJ. Life-history trade-offs favour the evolution of animal personalities. Nature. 2007:447:581-4. 
19. Wikelski M, Spinney L, Schelsky W, Scheuerlein A, Gwinner E. Slow pace of life in tropical sedentary birds: a common-garden experiment on four stonechat populations from different latitudes. Proc R Soc Lond B. 2003;270:2383-8.

20. Wiersma P, Muñoz-Garcia A, Walker A, Williams JB. Tropical birds have a slow pace of life. Proc Natl Acad Sci U S A. 2007:104:9340-5.

21. Ricklefs RE, Wikelski M. The physiology/life-history nexus. Trends Ecol Evol. 2002:17:462-8

22. Brodin T, Lind MI, Wiberg MK, Johansson F. Personality trait differences between mainland and island populations in the common frog (Rana temporaria). Behav Ecol Sociobiol. 2012;67:135-43.

23. Polverino G, Santostefano F, Díaz-Gil C, Mehner T. Ecological conditions drive pace-of-life syndromes by shaping relationships between life history, physiology and behaviour in two populations of eastern mosquitofish. Sci Rep-UK. 2018:8:14673.

24. Dubuc-Messier G, Réale D, Perret P, Charmantier A. Environmental heterogeneity and population differences in blue tits personality traits. Behav Ecol. 2017;28:448-59.

25. Dubuc-Messier G, Caro SP, Perrier C, van Oers K, Réale D, Charmantier A. Gene flow does not prevent personality and morphological differentiation between two blue tit populations. J Evolution Biol. 2018;31:1127-37.

26. Segev U, Burkert L, Feldmeyer B, Foitzik S. Pace-of-life in a social insect: behavioral syndromes in ants shift along a climatic gradient. Behav Ecol. 2017:28:1149-59.

27. Londoño GA, Chappell MA, Castañeda MR, Jankowski JE, Robinson SK. Basal metabolism in tropical birds: latitude, altitude, and the 'pace of life'. Funct Ecol. 2015;29:338-46.

28. Qu J, Fletcher QE, Réale D, Li W, Zhang Y. Independence between coping style and stress reactivity in plateau pika. Physiol Behav. 2018;197:1-8.

29. Dobson FS, Smith AT, Wang XG. Social and ecological influences on dispersal and philopatry in the plateau pika (Ochotona curzoniae). Behav Ecol. 1998;9:622-35.

30. Li ZW, Sun RY, Du JZ. Seasonal reproductive cycles in male plateau pika (Ochotona curzoniae). Acta Theriol Sin. 1998;18:42-9.

31. Nie H. Study on the evolutionary ecology of small herbivorous mammals: life history strategy of plateau pika (Ochotona curzoniae). PhD thesis. Zhejiang University, 2005.

32. Qu J, Liu M, Yang M, Zhang Y, Ji W. Reproduction of plateau pika (Ochotona curzoniae) on the Qinghai-Tibetan plateau. Eur J Wildlife Res. 2012;58:269-77.

33. Qu J, Li W, Yang M, Ji W, Zhang Y. Life history of the plateau pika (Ochotona curzoniae) in alpine meadows of the Tibetan plateau. Mamm Biol. 2013;78:68-72.

34. Qu J, Russell JC, Ji W, Yang M, Chen Q, Li W, et al. Five-year population dynamics of plateau pikas (Ochotona curzoniae) on the east of Tibetan plateau. Eur J Wildlife Res. 2017;63:51.

35. Koju NP, He K, Chalise MK, Ray C, Chen Z, Zhang B, et al. Multilocus approaches reveal underestimated species diversity and inter-specific gene flow in pikas (Ochotona) from southwestern China. Mol Phylogenet Evol. 2017;107:239-45

36. Wang $X G$, Dai KH. Natural longevity of plateau pika (Ochotona curzoniae). Acta Theriol Sin. 1989;9:56-62.

37. Wang $X$, Dai K. Studies on the population reproduction ecology of plateau pika. Zool Res. 1991:12:155-61.

38. Yin BF, Wang JL, Wei WH, Zhang YM, Cao YF. Population reproductive characteristics of plateau pika in alpine meadow ecosystem. Acta Therio Sin. 2004;24:222-8

39. Wang J, Zhang $Y$, Wang D. Seasonal thermogenesis and body mass regulation in plateau pikas (Ochotona curzoniae). Oecologia. 2006;149:373-82.

40. Yin B, Yang S, Wei W, Zhang Y. Male reproductive success in plateau pikas (Ochotona curzoniae): a microsatellite analysis. Mamm Biol. 2009; 74:344-50.

41. Wangdwei M, Steele B, Harris RB. Demographic responses of plateau pikas to vegetation cover and land use in the Tibet autonomous region, China. Mammal. 2013;94:1077-86

42. Qu J, Chen Q, Zhang Y. Behaviour and reproductive fitness of postdispersal in plateau pikas (Ochotona curzoniae) on the Tibetan plateau. Mammal Res. 2018;63:151-9.

43. Wu G, Duan A, Liu Y, Mao J, Ren R, Bao Q, et al. Tibetan plateau climate dynamics: recent research progress and outlook. Nat Sci Rev. 2015;2:100-16.
44. Huenneke LF, Clason D, Muldavin E. Spatial heterogeneity in Chihuahuan Desert vegetation: implications for sampling methods in semi-arid ecosystems. J Arid Environ. 2001;47:257-70.

45. Pérez i de Lanuza G, Carazo P, Font E. Colours of quality: structural (but not pigment) coloration informs about male quality in a polychromatic lizard. Anim Behav. 2014;90:73-81.

46. Martin JGA, Réale D. Temperament, risk assessment and habituation to novelty in eastern chipmunks, Tamias striatus. Anim Behav. 2008;75:309-18.

47. Réale D, Reader SM, Sol D, McDougall PT, Dingemanse NJ. Integrating animal temperament within ecology and evolution. Biol Rev. 2007;82:291-318.

48. Dingemanse NJ, Bouwman KM, van de Pol M, van Overveld T, Patrick SC, Matthysen $\mathrm{E}$, et al. Variation in personality and behavioural plasticity across four populations of the great tit Parus major. J Anim Ecol. 2012:81:116-26.

49. Hadfield J. MCMC methods for multi-response generalisedlinear mixed models: the MCMCglmm R package. J Stat Softw. 2010;33:1-22.

50. R Core Team. R. A language and environment for statistical computing. $R$ Foundation for Statistical Computing. 2017. https://www.r-project.org/.

51. Careau V, Montiglio P-O, Garant D, Pelletier F, Speakman J, Humphries M, et al. Energy expenditure and personality in wild chipmunks. Behav Ecol Sociobiol. 2015;69:653-61.

52. Galea LA, Kavaliers M, Ossenkopp KP. Sexually dimorphic spatial learning in meadow voles Microtus pennsylvanicus and deer mice Peromyscus maniculatus. J Exp Biol. 1996;199:195-200

53. Réale D, Martin J, Coltman DW, Poissant J, Festa-Bianchet M. Male personality, life-history strategies and reproductive success in a promiscuous mammal. J Evol Biol. 2009;22:1599-607.

54. Meng FD, Jiang LL, Zhang ZH, Cui SJ, Duan JC, Wang SP, et al. Changes in flowering functional group affect responses of community phenological sequences to temperature change. Ecology. 2017;98:734-40.

55. Luttbeg B, Sih A. Risk, resources and state-dependent adaptive behavioural syndromes. Philos Trans R Soc B Biol Sci. 2010;365:3977-90.

56. Sih A, Mathot KJ, Moirón M, Montiglio P-O, Wolf M, Dingemanse NJ. Animal personality and state-behaviour feedbacks: a review and guide for empiricists. Trends Ecol Evol. 2015;30:50-60.

57. Savolainen O, Lascoux M, Merilä J. Ecological genomics of local adaptation. Nat Rev Genet. 2013;14:807.

58. Refsnider JM, Qian SS, Streby HM, Carter SE, Clifton IT, Siefker AD, et al. Reciprocally transplanted lizards along an elevational gradient match light environment use of local lizards via phenotypic plasticity. Funct Ecol. 2018; 32:1227-36.

59. McGhee KE, Pintor LM, Bell AM. Reciprocal behavioral plasticity and behavioral types during predator-prey interactions. Am Nat. 2013;182:704-17.

60. Zhao DP, Feng PS. Temperature increase impacts personality traits in aquatic non-native species: implications for biological invasion under climate change. Curr Zool. 2015;61:966-71.

61. Villegas-Ríos D, Réale D, Freitas C, Moland E, Olsen EM. Personalities influence spatial responses to environmental fluctuations in wild fish. J Anim Ecol. 2018;87:1309-19.

62. Biro PA, TG J, Beckmann C, Ujvari B, Thomas F, Post JR. Metabolic scope as a proximate constraint on individual behavioral variation: effects on personality, plasticity, and predictability. Am Nat. 2018;192:142-54.

63. Pacifici M, Visconti P, Rondinini C. A framework for the identification of hotspots of climate change risk for mammals. Glob Chang Biol. 2018;24: 1626-36.

\section{Publisher's Note}

Springer Nature remains neutral with regard to jurisdictional claims in published maps and institutional affiliations. 